\title{
UN TIENTO DE PERAZA ENTRE PAPELES DE SAN ZOILO DE CARRIÓN
}

\author{
Ismael FERnÁNDEZ DE LA CUESTA \\ Catedrático del Real Conservatorio de Música de Madrid
}

\begin{abstract}
The restauration carried out in the old monastery of San Zoilo de Carrión (Palencia) allowed to recover several musical extracts, among which we must point out a tiento from Peraza. Due to the stylistic complexity of this tiento, we may assume that its current aspect is the result of several modifications carried out by subsequent organists who would introduce in it elements of modernity. Nothing prevents us, therefore, to attribute the primitive form this work may have had originally to Francisco Guerrero's friend, the first important musician from the Peraza family, Francisco the father (1564-1598).
\end{abstract}

\section{Resumen}

La restauración llevada a cabo en el antiguo monasterio de San Zoilo de Carrión (Palencia) permitió recuperar diversos fragmentos musicales entre los que destaca un tiento de Peraza. La complejidad estilística de este tiento permite suponer que la forma que exhibe en la actualidad es fruto de sucesivas acciones de organistas posteriores, quienes pudieron introducir en ella elementos de modernidad. Nada impide, por tanto, atribuir la primitiva forma que pudo tener esta obra en origen, al amigo de Francisco Guerrero, primer músico importante de la saga de los Peraza, Francisco el padre (1564-1598).

En el concierto que siguió al acto de mi ingreso como Académico numerario en la Real de Bellas Artes de San Fernando, 11 de junio de 2000, los asistentes pudieron escuchar como primicia un tiento de Peraza, interpretado por Miguel del Barco en el órgano de la Academia. El hallazgo de esta pieza había tenido lugar algunas semanas antes, mientras se llevaban a cabo las obras de restauración del edificio del antiguo monasterio de Carrión de los Condes, Palencia. Tras examinar un amasijo de papeles ocultos entre las ruinas con signos de variados usos higiénicos, pude reconocer este tiento en una de las hojas que llevaba el siguiente encabezamiento: "quarto tono media dulçayna de peraza a dos tiples". La música venía escrita en tablatura española de órgano. Aunque la hoja estaba bastante perdida y la cifra muy borrosa, logré transcribir y recomponer el tiento.

Con criterio digno de ser imitado, los actuales propietarios del noble edificio y la Fundación Santa María la Real de Aguilar de Campóo (Palencia) a quien había sido encomendada la restauración, decidieron emprender un estudio arqueológico de las diversas estancias antes de iniciar las obras de adaptación del edificio a su nuevo uso: una hospedería. El equipo técnico de la Fundación 
dirigido por el arquitecto Juan Carlos Prieto, el arqueólogo Jaime Nuño y José Antonio Perrino, párroco de la iglesia y gerente de la "Hospedería San Zoilo", llevó a cabo su trabajo con unos resultados que fueron, en mi opinión, tan espectaculares como inesperados, al menos en lo que se refiere a la música.

\section{Breve noticia histórica de San Zoilo de Carrión}

San Zoilo de Carrión fue uno de los monasterios benedictinos más importantes y más ricos de España. Su historia de más de un milenio ha sido muy rica y determinante en Castilla. Lamentablemente no disponemos de una monografía moderna sobre el particular. El estudio más completo sigue siendo todavía, a mi parecer, el de Ramírez de la Helguera publicado en $1900^{1}$.

De probable origen visigodo, el monasterio de Carrión aparece documentado por vez primera en 1047, año en que consta una importante donación de los Condes de Carrión, Gómez Díaz y Teresa. De esta época consta un antifonario de liturgia hispano-visigótica perteneciente a este monasterio, algunas de cuyas hojas se conservan hoy en la Biblioteca Nacional de Madrid (Mss. 11556). Algún fragmento, no musical, recuperado en la reciente restauración pertenece también a esta época. El monasterio tenía como patrón a San Juan Bautista, pero enseguida fue puesto bajo la advocación de San Zoilo, al recibir las reliquias de este santo en el siglo XI. Los benedictinos llevaron allí una vida pujante hasta que fueron exclaustrados en 1835. Años después, en 1854, las instalaciones monásticas, convertidas en colegio de segunda enseñanza y casa de formación, fueron ocupadas por los jesuitas. En los últimos tiempos éstos han abandonado Carrión. Una parte de los edificios antiguos es hoy propiedad privada.

Apenas quedan restos monumentales del monasterio medieval. En cambio, son muy notables las edificaciones de los siglos XVI y XVII. Destaca su claustro de estilo plateresco cuya construcción fue iniciada por Juan de Badajoz en 1537. La iglesia posee un órgano fechado en 1716 que necesita una restauración.

\section{Fragmentos musicales encontrados en Carrión}

Entre las hojas de papel rescatadas en la restauración del edificio once de ellas aparecen con música, muy perdida, de muy diversa índole. He aquí una breve descripción:

1. Fragmento, realmente muy pequeño $(8 \times 8 \mathrm{~cm}$.), de un Pasionario polifónico de principios del siglo XVI. Contiene parte de la turba y el soliloquium de la Pasión Según San Marcos, que se cantaba en la Misa del Martes Santo ([recto], Marcos, 14,5; [verso], Marcos, 14,14). Notación blanca brevis-longa. Faltan claves. Tiene un interés meramente testimonial, por su pequeñez, aun-

1. R. Ramírez de la Helguera: El Real Monasterio de San Zoilo de la ciudad de Carrión de los condes ante la historia y el Arte, Palencia 1900. 
que puede tratarse de uno de los ejemplos de Pasión polifónica más antiguo de España y probablemente de Europa.

2. Fragmentos de las partes de un villancico de los llamados "de portugueses", de los que se cantaban en los Maitines de Navidad.

a) "gesolrreud organo" . "portuguesiño". "coplas de cuatro en cuatro". Clave de "do" en la tercera línea del pentagrama.

b) "alto $2^{\circ}$ choro". "ay que me morro, ay que me fino... (se repite sucesivamente esta exclamación para terminar:) de amor do menino". Clave de "do" en la tercera línea del pentagrama.

c) Con otra grafía: "ya llega para el órgano" (?). "ai que me morro". Único texto. Clave de "fa" en la cuarta línea del pentagrama.

3. Papel. Villancico.

[recto]: "10 tiple. diálogo". "Dulce jesus, dulce jesús, donde estabais...". Rúbrica: "aqui falta la Responsion, atras estan las coplas".

[verso]: "Quien sabe lo que es amor". Clave de "sol" en la segunda línea del pentagrama.

4. Papel. Villancico. "[coplas. alto]: $1^{\text {a }}$ Alma miña fermosa". " 2 a . Nao te mostres engrata". " $3^{\mathrm{a}}$. Pois te chamo, non sejas tao crua". "Ay quem dezeja". Clave de "do" en la segunda línea del pentagrama.

5. Papel. Villancico. "[tenor] Como catan y disen." "[coplas.] 1 $1^{\mathrm{a}}$. digan a profia (sic) el sielo y tierra". " 2 a . digamos pidos (sic, pro "pios"? ${ }^{2}$ ) los de la tierra". " $3^{\text {a }}$ dizen de contento el sielo y tierra". "A mi dios mil dulsuras". Clave de "do" en la cuarta línea del pentagrama.

6. Papel. Canción (villancico). "A 3". "tiple". "Esta Virgen se lleua la gala la gala y flor".... "R/. Por ser limpia y pura en su concepción". Clave de "sol" en segunda línea del pentagrama.

7. Papel. Canción (villancico). "[Bajo]. Maioral que mi bien que mi bien desea”. Clave de "fa" en la cuarta línea del pentagrama.

8. Hoja suelta.

[recto]. Antífona incompleta del Magníficat de la Fiesta de Todos los Santos $1^{o}$ de noviembre. Notación cuadrada blanca, breves: [Angeli Archangeli] ... [do]minationes, principatus et potestates... intercede pro nobis".

[verso] (poema sin música).

Gran marabilla Señores

obra Dios oy en el mar

pues como Carmen a dar

llega por arena flores.

De Zelos muerto bivía

el mar de la tierra tanto

2. "Pido: acto de pedir alguna cosa. Es voz jocosa e inventada". Diccionario de Autoridades, 1737. 
que entre bramidos y llanto

bien mal el suyo encubría

Pero ya della en porfia

conquistando el cielo a olores

hecho unas al biento altar (?)

Pues como carmen a dar

[llega por arena flores].

\section{Papel.}

[recto]. Es un verso de la Secuencia Lauda Sion perteneciente a la Fiesta del Corpus Christi: "Quantum potes tantum aude ....". "Alleluya, ij, allel[luia]". Melodía de tradición española. Siglo XVII. Notas redondas y blancas. Sigue: "ista est prosa quantum potes" y, a continuación, dicha prosa, escrita en cifra, está armonizada para ser interpretada al órgano. (Ver transcripción en el Libro de música, Homenaje a Ramón González de Amezúa en su $80^{\circ}$ cumpleaños, Madrid, Real Academia de San Fernando, 2001).

[verso]. Parte de una canción (villancico). Texto borroso. Clave de "do" en la segunda línea del pentagrama. Notas redondas y blancas .

10. Hoja suelta. Tamaño folio. "quarto tono media dulçayna de peraza a dos tiples". Obra para órgano de teclado partido, escrita en cifra española, a cuatro voces. [recto] y [verso]. Siglos XVII-XVIII. Algunos compases están muy borrosos y tiene perdidas algunas cifras en el interior así como la esquina inferior izquierda del recto, derecha del verso de la hoja (ver comentario, más abajo; transcripción en el Apéndice I).

11. Hoja suelta. Tamaño cuartilla. Cuadro sinóptico de las figuras del canto figurado. Siglo XVIII. "figuras. Máxima. longa...” y demás signos de la notación, entre otros: "bemol fa. bquadrado mi. canon. repeticion. guion. calderon".

\section{Peraza y el tiento de "quarto tono media dulçayna"}

Entre todos los fragmentos musicales que acabo de reseñar destaca el número 10. Contiene un tiento para órgano que, según el título, es de Peraza.

El apellido Peraza señala toda una dinastía de músicos que no ha sido posible desentrañar del todo, aunque mucho se ha avanzado tras las pesquisas genealógicas realizadas por Robert Stevenson $^{3}$, Dionisio Preciado ${ }^{4}$, Louis Jambou ${ }^{5}$ y Juan Ruiz Jimeno ${ }^{6}$. El apellido Peraza es el de una

3. Robert Stevenson: La música en las catedrales españolas del siglo de oro, Madrid, Alianza, 1993, pp. 188-190.

4. Dionisio Preciado: "En torno al organista Francisco Peraza I (1564-1598) y a su "tiento de medio registro alto". Nasarre. XIV, 1998, 299-311.

5. Louis JAMBOU: "Reflexiones y documentos sobre dinastías de Maestros de capilla y organistas de los siglos XVIXVII", Nasarre, XII, 1996, n. 2, 161-184.

6. Juan Ruiz Jimeno: "La dinastía de los Peraza. Nuevos datos para la biografía de Jerónimo Peraza II", Cuadernos de arte, Universidad de Granada, 26, 1995, 53-63. 
saga de músicos activos en la segunda mitad del siglo XVI y primera del siglo XVII: dos hermanos, Francisco y Jerónimo, y dos hijos de cada uno, llamados asimismo Francisco y Jerónimo. Los padres fueron respectivamente organistas de las catedrales de Sevilla y de Toledo. Francisco Peraza, el padre, organista de la catedral de Sevilla en tiempos de Francisco Guerrero fue el músico más importante de la dinastía. En sus pocos años de vida (1564-1598), este gran organista consiguió, en efecto, gran celebridad. Amigo del Compositor Francisco Guerrero y maestro de organistas como Francisco Correa de Araujo, participó en los cenáculos y tertulias organizadas por Francisco Pacheco, suegro de Velázquez, donde se discutían los nuevos estilos en música que preconizaban el posteriormente llamado barroco. Pacheco incluye el retrato de Francisco Peraza en su Libro de descripción de retratos de ilustres y memorables varones, Sevilla, 1599. Francisco Peraza murió a los 34 años de edad, en 1598, un año antes que el insigne polifonista.

Apenas tenemos otras noticias sobre Francisco Peraza que las que proporciona Francisco Pacheco. Nacido en 1564 en tierras de Castilla y León, probablemente en Salamanca, llegó a Sevilla procedente de Toledo. Era, según Pacheco, un músico extraordinario, muy admirado por sus contemporáneos: "hazia tantas diferencias sobre lo que (Francisco) Guerrero avia pedido, que procedia en infinito, con admiracion de los circundantes, juzgando que era gracia sobrenatural como monstruo en aquella facultad"?

Su vida de clérigo organista de la catedral Sevilla, la catedral más importante, quizá, de España en aquellos momentos, fue muy azarosa. De sus relaciones anticanónicas con la noble Juana Bautista de Escobar (identidad ocultada durante toda su vida bajo el apellido Altamirano) nació su hijo Francisco.

A pesar de su fama universal, ni una sola nota de música nos ha quedado de él con total certeza. Algunos musicólogos han atribuido a Francisco Peraza un par de piezas. Es posible que algunas de las obras para órgano de la época que hoy aparecen anónimas fueran compuestas por este gran organista.

\section{Paternidad del tiento de Carrión}

Hasta hoy tan sólo se ha atribuido con cierta verosimilitud a Francisco Peraza, el padre, un Tiento de medio registro alto de tono I. Pero Dionisio Preciado ${ }^{8}$ duda mucho de que sea realmente suya la autoría. Según él, esta obra podría pertenecer a cualquiera de los organistas de la misma dinastía pues, de hecho, posee procedimientos que están en consonancia con el estilo barroco y no con el de su tiempo.

Usando la argumentación del sabio maestro Preciado, podríamos decir que el tiento encontrado de Carrión no es del Peraza organista de la catedral de Sevilla amigo de Francisco Guerrero. En efecto, también hay en dicha obra elementos y recursos estilísticos que podríamos considerar

7. Francisco PACHECO: Libro de descripción de retratos de ilustres y memorables varones, Sevilla, 1599, reed., Sevilla, 1881-1885, n $^{\circ} 46$. pp. 329-333.

8. D. PRECIADO: ibid. 
tardíos (omito emplear expresamente en este caso el término "barroco"), especialmente, imitaciones, progresiones y otros detalles impropios de una época tan temprana como la de Francisco Peraza, el padre. Pero también se advierte en algunas fórmulas, especialmente en las incoativas y conclusivas, un cierto arcaísmo. Por otro lado, el desarrollo de la obra adolece, a mi juicio, de alguna incoherencia en la transición de unos pasajes a otros.

Todo lo cual me lleva a hacer ciertas reflexiones sobre la obra encontrada en Carrión y, asimismo, sobre el Tiento de medio registro alto de tono I que estudia Preciado.

Muchas veces he sostenido que la sociedad de tiempos anteriores al siglo XIX "consumía", sobre todo, música contemporánea, y no tanto música del pasado. (No hay que entender el gregoriano como música del pasado, por creerse de inspiración divina y, consiguientemente, de sempiterna actualidad). Los compositores eran, las más de las veces, músicos prácticos, esto es intérpretes, cantores, instrumentistas. Por tal condición se veían en la necesidad de crear, hacer música para la función en la que ellos mismos eran actores. Podríamos traer aquí, a título de ejemplo, a excelsos compositores como A. de Cabezón, C. de Morales, J. S. Bach, etc. Ahora bien, sucesores, discípulos y conocidos de aquellos grandes músicos que habían alcanzado merecida fama entre sus contemporáneos como intérpretes y compositores, no sólo imitaron la técnica de éstos sino también hicieron lo posible por tener en sus manos las obras salidas de la inspiración de sus maestros. Así, Hernando de Cabezón pasó a cifra "las migajas que caían de la mesa" de su padre Antonio. A veces los propios compositores se preocupaban de fijar por escrito sus obras, notablemente dándolas a las mejores imprentas para obtener una mayor difusión, como hizo Francisco Guerrero' ${ }^{9}$. Es de suponer que la puesta por escrito de la música de estos grandes intérpretes e improvisadores se hacía procurando la mayor fidelidad posible a la forma establecida por el maestro. Pero no toda la música de los grandes maestros había llegado a imprimirse ni todos los centros disponían de los impresos. Por eso, la difusión de la música de los grandes maestros se efectuaba mediante la copia manuscrita. Reflejo de la interpretación contemporánea, la música de viejos compositores, copiada, verbi gratia, por los maestros de capilla para la liturgia de su catedral, se veía inevitablemente sometida a dos impulsos opuestos: el respeto a la forma dada por el viejo compositor y el influjo de los estilos reinantes. Este doble impulso conducía a una suerte de compromiso en las versiones resultantes de las copias sucesivas, donde la trama y el sustrato de la pieza original se veía salpicada de elementos y recursos contemporáneos.

Las obras instrumentales solistas estaban, obviamente, más expuestas a la intervención del intérprete de turno que las corales o instrumentales de grupo, porque la intervención en éstas, a menos que actuase directamente en la copia el maestro de capilla, necesitaba un acuerdo previo entre los diversos intérpretes. En cualquier caso, obras de tecla se verían, probablemente, muy expuestas a la introducción de elementos modernos por el propio organista, más de lo que parecen dar muestra las copias.

Partiendo, pues, del título que precede al tiento cifrado en la hoja de Carrión de los Condes, Quarto tono media dulçayna de Peraza a dos tiples, donde consta la atribución de la obra a Pera-

9. R. Stevenson: La música en las catedrales españolas del siglo de oro, pp. 200-211. 
za, debemos concluir que uno de los músicos de este apellido fue el autor de este tiento. Ahora bien, si aplicamos la reflexión anteriormente expuesta, no hay motivos que nos impidan concluir que el original fue de Francisco Pacheco el padre. Compuesta por este u otro gran organista, la obra pudo tener en lo sucesivo, no sólo en tiempos de los otros Peraza conocidos sino también posteriormente, intervenciones diversas para su adaptación a los nuevos tiempos y estilos, las cuales producirían los elementos de modernidad que advertimos en la obra. Atendiendo, por tanto, a estas consideraciones, me quedo con la idea de que un original de este Quarto tono media dulçayna es atribuible a Francisco Peraza el padre, mientras no haya otras razones convincentes en contra. La cuestión, quizá, insoluble es la de saber cuánto queda de aquel posible original en la versión del tiento descubierto en Carrión de los Condes.

\section{Transcripción y reconstrucción}

Como he señalado al hacer la descripción, la obra está copiada en cifra española en una hoja por las dos caras. Me parece muy arriesgado proceder a una atribución cronológica clara de la copia partiendo únicamente de la escritura. Me aventuro a pensar, no obstante, que la hoja de Carrión pudo ser escrita dentro ya del siglo XVIII. Tiene partes muy borrosas, y alguna parte perdida. He procedido, por tanto, a la transcripción intentando afirmarme, con razones externas e internas, en la versión que propongo. Las notas y pasajes que faltan, cuando la hoja está totalmente perdida, los he suplido a mi manera. He contrastado opiniones con mis sabios amigos José Sierra y Dionisio Preciado, con mi Director y catedrático de órgano Miguel del Barco y con mi joven alumno, pero ya maestro y buen intérprete, Jafet Ortega. Desde aquí les expreso mi gratitud por su ayuda y les reitero mi amistad.

La presentación de la obra obedece a los criterios más universales de edición en este tipo de trabajos. Escribo en el texto la lección que me parece más correcta y relego a nota cualquier tipo de incidencia textual y los que me parecen errores de copia. 


\section{APÉNDICE I}

\section{Quarto Tono: Media Dulçaina a dos tiples}
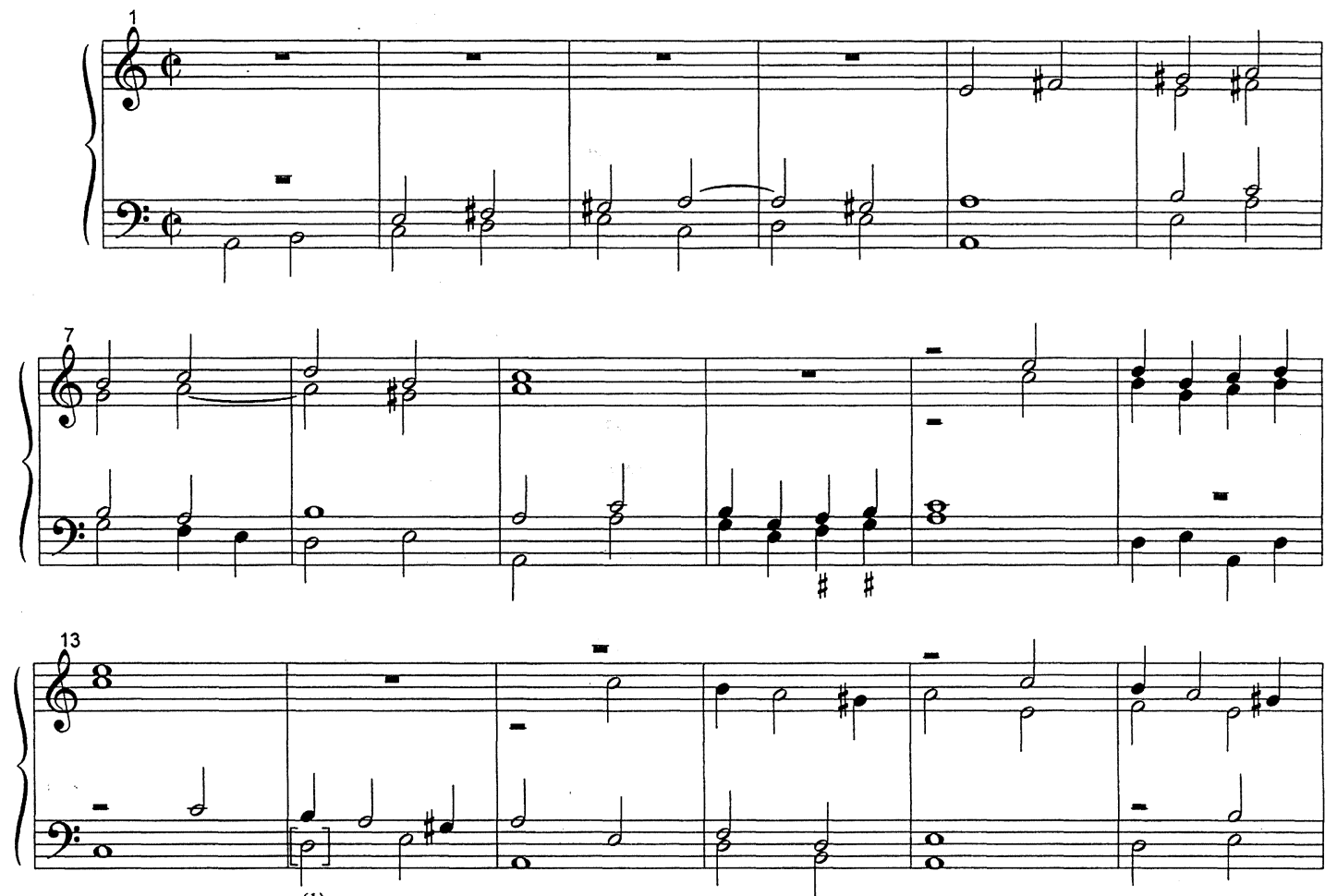

(1)

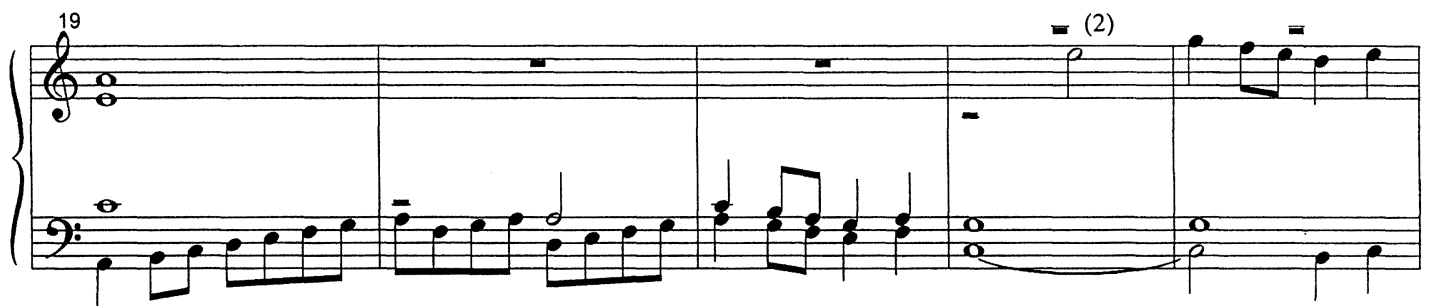

(1) Las notas o pasajes puestos entre corchetes son de lectura dudosa, o son restituidos por existir laguna en el original.

(2) La segunda voz inicia el c.22 con un "mi" redundante que hemos suprimido. 

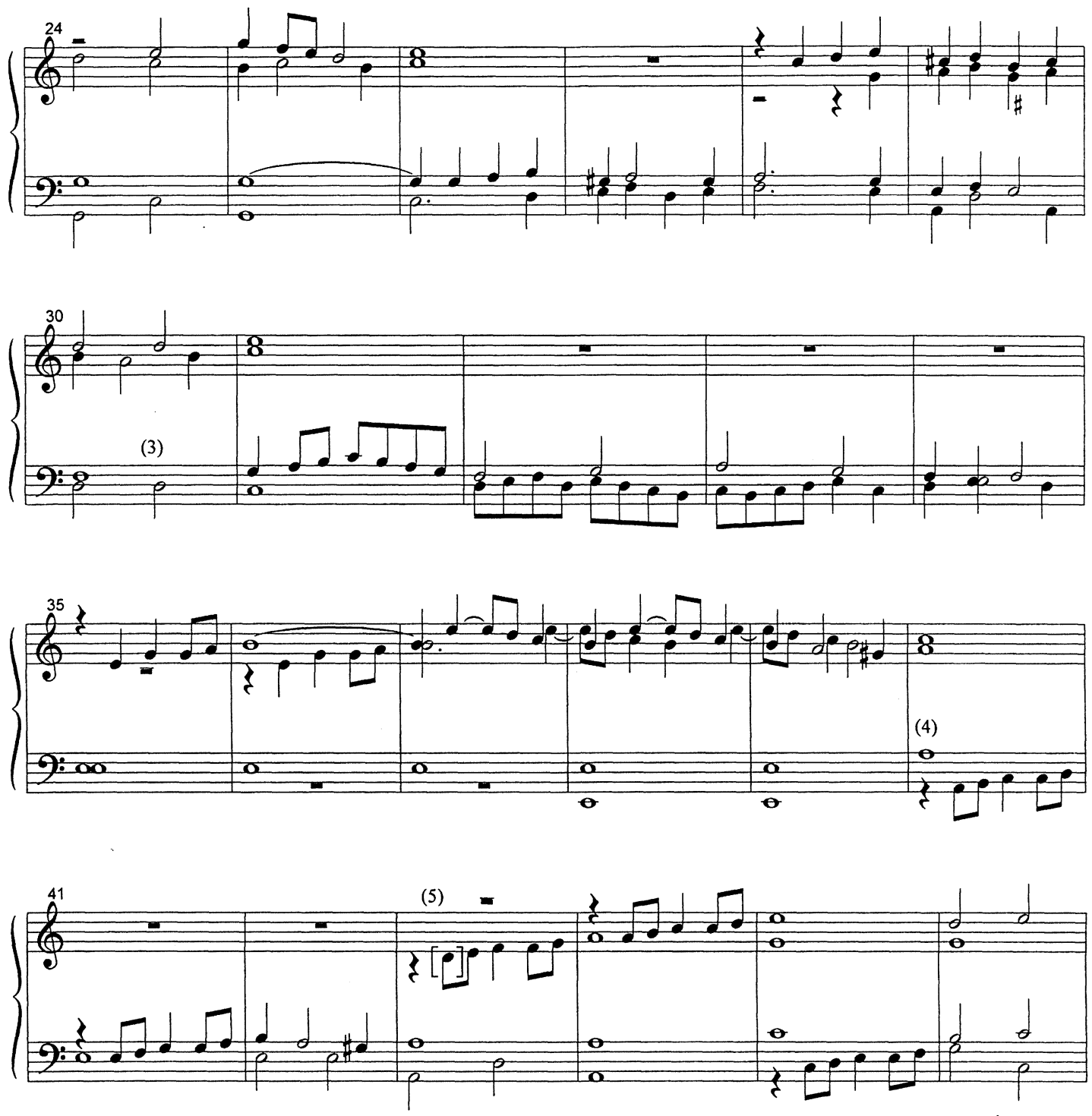

(3) Cuarta voz del c.30 "sol" por "re".

(4) En el original estos motivos, en los compases 40,41, 44, 45, se escriben así: |l CPP P

(5) c. 43, segunda voz "mi" negra por "re-mi" corcheas. 

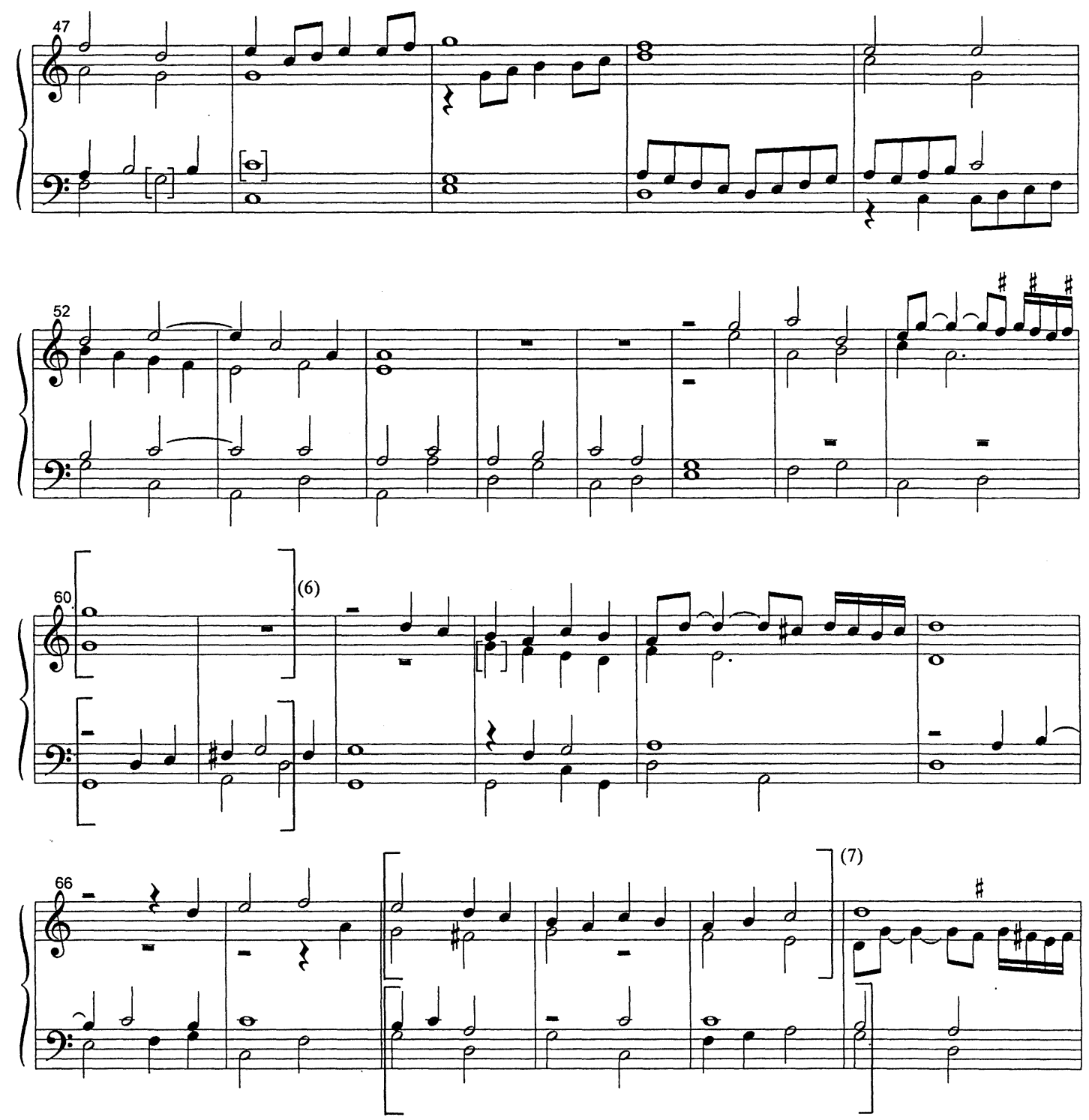

(6) Versión restituida. Falta un trozo de hoja

(7) Versión restituida. Falta un trozo de hoja

() 2000 Sintonia S.A. 

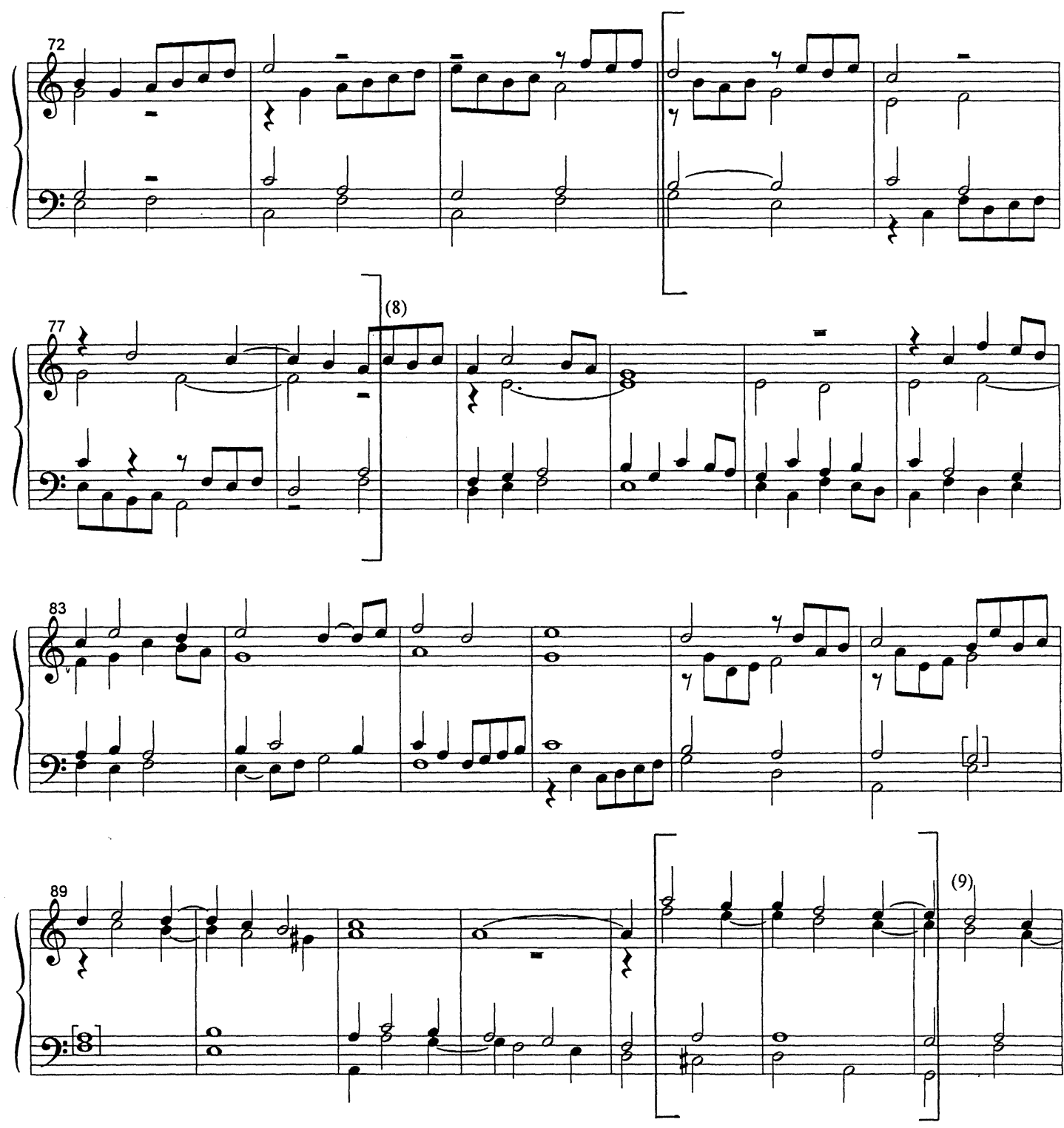

(8) Versión restituida.

(9) Lectura dudosa.

(๑) 2000 Sintonia S.A. 

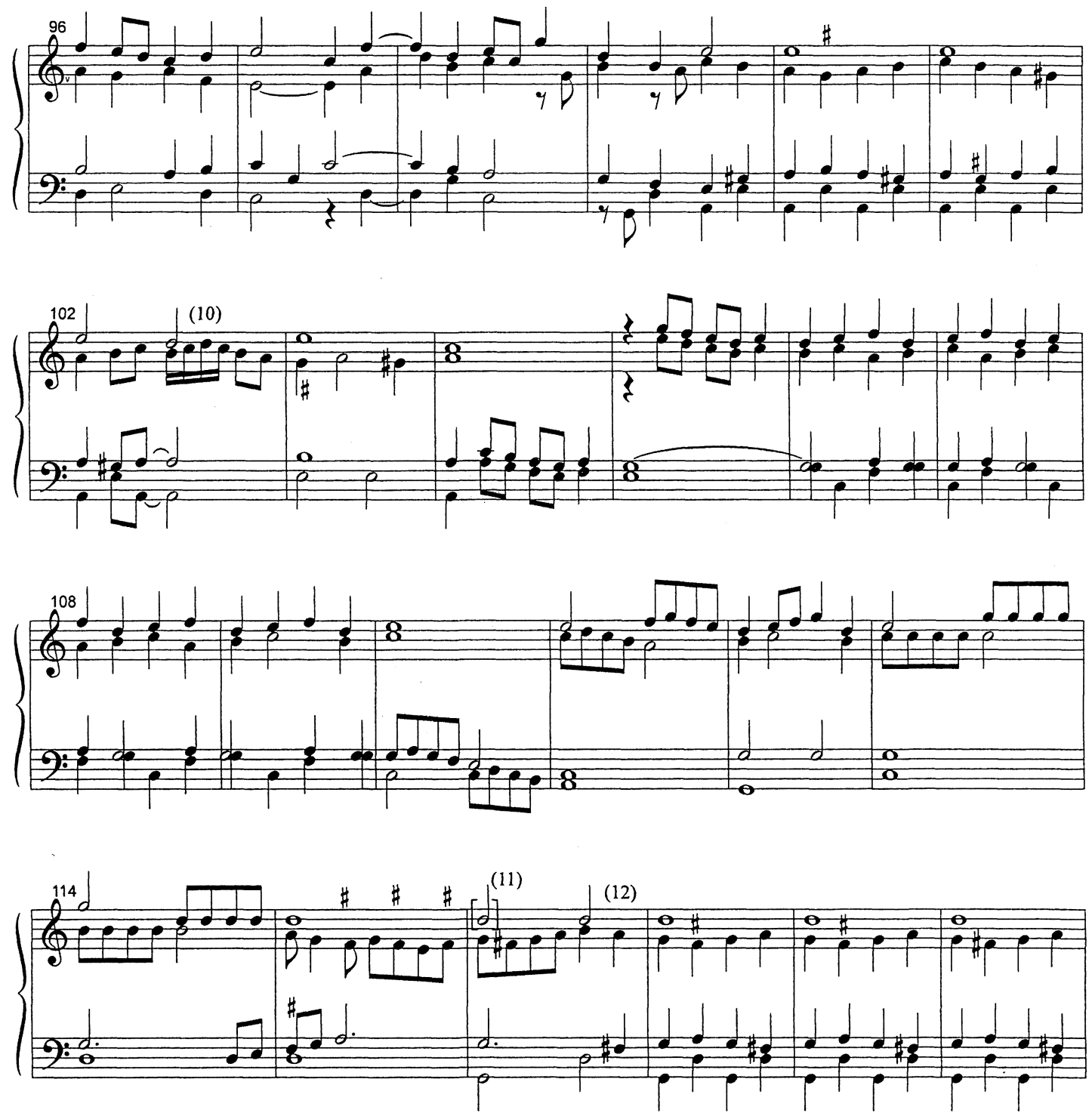

(10) Este pasaje podría leerse mejor asi:

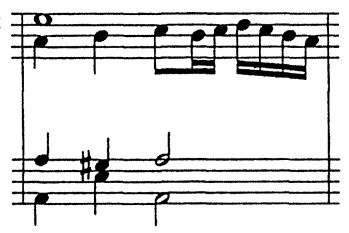

(11) Lectura dudosa

(12) La última negra del compás es" do" en el original 

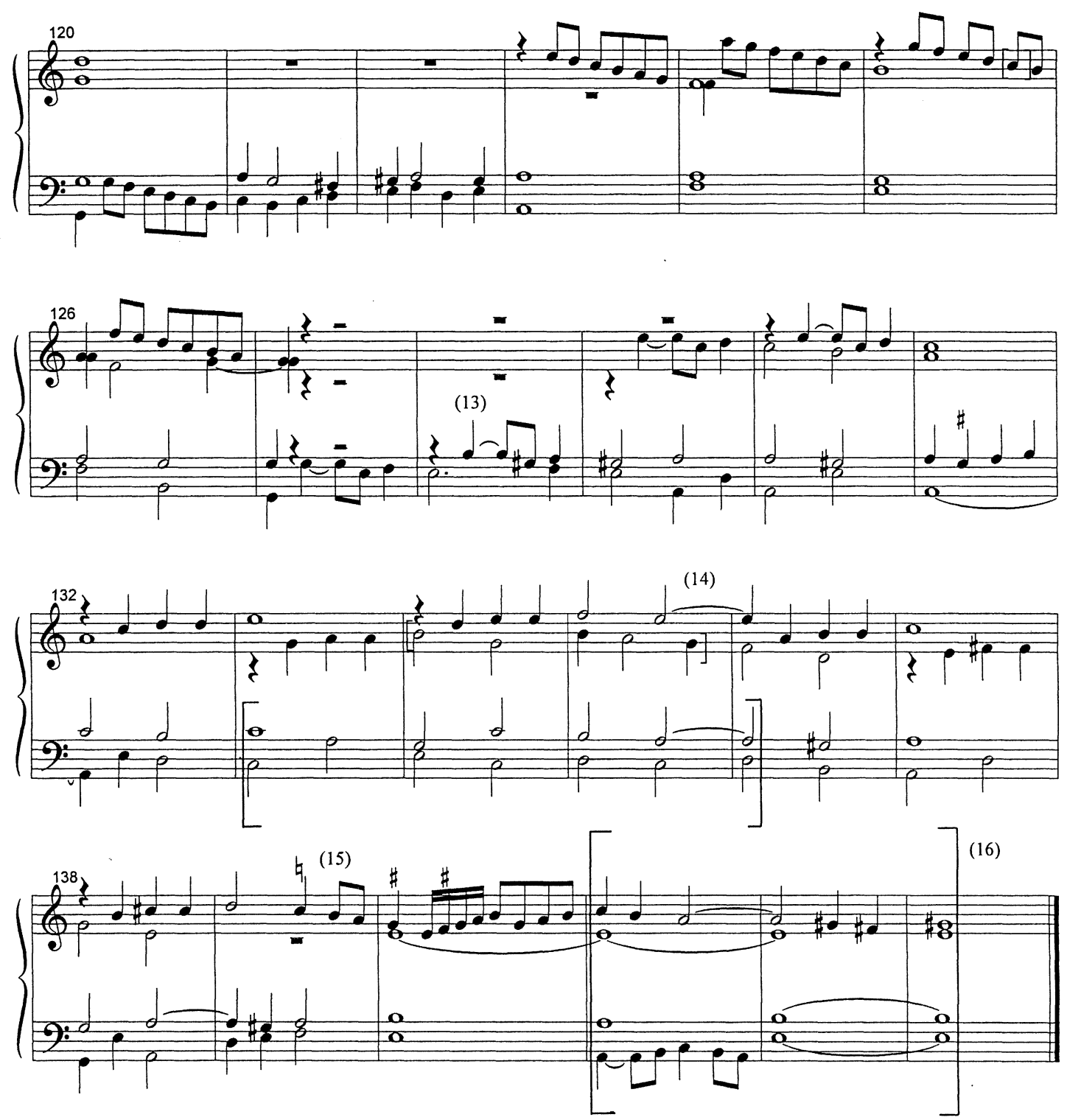

(13) la tercera voz tiene en el original la figuración siguiente: It $\rho$ P |

(14) Versión restituida. Falta un trozo de hoja.

(15) $\rho \rho \rho$ en el original.

(16) Versión restituida. Falta un trozo de hoja. 